\section{Examining the Effect of Organizational Culture on the Relationship between Supply Chain Quality Management Practices Adoption and Performance of Private Hospitals in Kenya}

$\mathrm{PhD}$ candidate, Department of Management

Science, School of Business University of Nairobi, Kenya

\section{Stephen Odock}

Senior Lecturer, Department of management science, School of Business University of Nairobi, Kenya

\section{James Muranga Njihia}

Associate Professor, Department of Management science, School of Business University of Nairobi, Kenya

\section{Peter K'Obonyo}

Professor, Department of Business Administration, School of Business University of Nairobi, Kenya

Submitted: 07 October 2020

Accepted: 05 November 2020

Published: 30 November 2020

Corresponding author:

Tobias Okoth Ondiek

DOI: 10.19044/esj.2020.v16n31p147

(c)

Copyright 2020 Tobias Okoth Ondiek et al. Distributed under Creative Commons BY-NC-ND 4.0 OPEN ACCESS

\begin{abstract}
Health care institutions have complex global supply networks and organizations that have heterogenous cultural configurations. There are a number of studies that have directly linked supply chain quality management practices in the manufacturing sector and other service firms to organizational performance. However, minimal research has been done to examine the role of corporate culture in the relationship. Moreover, there is need to empirically confirm effect of corporate culture in private hospitals in Kenya where provision of quality and affordable health care remains a challenge. Corporate culture fit between organizations serves as a thread that ties firms together. The study was conducted in order examine the effect of organizational culture on the relationship between supply chain quality management practices adoption and performance of private hospitals in Kenya. Positivist research orientation and descriptive cross-sectional research design guided the research process. Raw data was collected from management staff tasked with supply chain decision making responsibility in the hospitals. A response rate of $70.51 \%$ was realized. Normality, collinearity, homoscedasticity and autocorrelation constituted model diagnosis. Hypothesis was tested using model fit indices and significance of path coefficient. The findings indicate that corporate culture has significant positive effect on the relationship. The study concluded that right corporate culture among supply chain partners both internally and externally serves as catalyst
\end{abstract}

How to cite this article

Ondiek, T.O.. et al, (2020). Examining the Effect of Organizational Culture on the Relationship between Supply Chain Quality Management Practices Adoption and Performance of Private Hospitals in Kenya. European Scientific Journal, ESJ, 16(31), 147. https://doi.org/10.19044/esj.2020.v16n31p147 
while implementing SCQM practices to bring about improved performance. It is therefore recommended that for private hospitals to benefit more from improved performance upon adopting SCQM practices, they must ensure homogeneity of cultural configurations internally and externally. In addition, the study provides future researchers with a useful conceptual and methodological reference that can be used in the pursuit of further studies particularly in the area of both supply chain and quality management with specific reference to the corporate culture as a moderating variable.

Subject: Business, Investments

Keywords: Corporate culture, supply chain quality management practices, organizational performance

\section{Introduction}

Organizations have unique internal human behavior that may need significant realignment to contend with new scientific management paradigms. In particular, SCQM practices implementation may call for inter and intra organizational cultural compatibility in order to yield desired performance outcomes (He, Sun, Ni \& Ng, 2017; Lee, Lee \& Schniederjans, 2011). This is premised on the understanding that adoption of such management philosophy entails formation of business relationships with other organizations with predetermined cultural patterns. Harmonization of interfirm culture plants a conducive environment and framework that cements strategic business alliances which may amplify performance outcomes (Cadden, Humphreys \& McHugh, 2010). Indeed, there are several studies that have been conducted on the effect corporate culture in both strategy implementation by organizations and performance in different contexts (Fawcett, Magnan, \& McCarter, 2008; Lee \& Yu, 2013; Abd, Kamarulzaman \& Sambasivan 2013) However, a similar research is not apparently reported in the uniquely characterized hospital environment in Kenya.

\subsection{Corporate Culture}

Culture refers to configurations of morals and philosophies that are demonstrated in practices, behaviors and artefacts that are communal in organizations (Cadden et al., 2010). The corporate culture is thus a reflection of the beliefs and values of the corporate leaders and the subjects. It can therefore directly be linked to firm's operations strategy. Meaning that, culture is a form of organizational social environment in which organizational operating strategy is embedded. More often, organizational cultures are shaped by understandings and beliefs of the entire firm population and their stakeholders. It is also argued that culture shapes behavior of the employees among themselves and towards entire business associates. Culture can be described as implicit, unifying, 
invisible, intrinsic and informal consciousness organizational substance which explains meaning and direction of an organization.

The are several categories of culture that different authors have reported in literature. Sun (2008) compartmentalized culture into three layers with outer layer being linked to values about strategies, missions and objectives of the organization. The middle layer is attributable to beliefs on the issues that firm employees normally narrate. The inner core reflects on the organizational life that people find difficult to recall and explain. According to Abd et al. (2013), four categories of corporate culture are identifiable. First, competitive culture which emphasizes demanding goals, competitive advantage, marketing superiority and profits. Second, is the entrepreneurial culture which stresses innovation, risk taking, high levels of dynamism and creativity. Third is the bureaucratic culture which underscores formalization, rules, standard operating procedures and hierarchical coordination. Finally, consensual culture with tradition, loyalty, personal commitment, extensive socialization, teamwork, self-management and social influence underlined as dominating elements.

Among the typical beliefs that shape organization's culture is position a firm takes to actively and visibly pursue superior quality in the entire array of activities. Adherence to quality of service design and products in addition to conformance to specification is a reflection of organizational culture. The same is therefore regarded as mandatory substance necessary for designing and implementing successful strategies such as SCQM practices to yield best performance. As such, all firms within a supply network must have common knowledge and culture on what constitutes quality. Therefore, cultural homogeneity and compatibility is a pilar prerequisite for aligning intra-firm practices with inter-organizational relationships (Fawcett et al., 2008). This in effect implies that inability to integrate corporate cultures of quality along supply chain is a potential foundation for failure by the firms that attempt to implement SCQM practices. Cultural fit between business partners enable them to share information fast and manage partnerships relating to suppliers and customers (Cadden et al.,2010; Prajogo \& McDermott, 2011; Lee \& Yu, 2013). Low productivity, lack of customer satisfaction, poor financial performance results and increased level of conflicts have been shown to emerge from cultural incongruence despite adoption of effective and timetested business ideas such as SCQM practices (Mello \& Stank, 2005; Fawcett et. al., 2008; Meirovich, 2010; Deshpande \& Farley, 2013).

\subsection{Supply Chain Quality Management Practices}

The primary goal of integrating total quality management (TQM) into a supply chain is to sustain value addition to customers and all other prime stakeholders. This approach has been conceptualized as supply chain quality 
management (SCQM) while the activities embodied in this management strategy are referred to as SCQM practices. Three main sets of supply chain quality management practices are identifiable (Zeng, Phan, \& Matsui, 2013). First, there is internal quality management or internal process management. Second, is the interaction with suppliers which constitutes upstream arm of supply chain or upstream quality management. Lastly, firms have to manage quality upon interacting with their customers or downstream quality management.

Common supply chain quality management practices are customer focus, supplier relationship management, information sharing, postponement, process management and coordination. Focusing on customers enables firm to concentrate on making products that are appealing to their customers more than their competitors. This guarantees customer loyalty and their willingness to pay premier prices for the organizations' outputs (Talib, Rahman \& Qureshi, 2011). Supplier relationship management denotes selection, development, monitoring and collaborating with suppliers. It leads to long term coexistence that enables firms in the chain to communally avoid risks and share benefits (Prajago et al., 2012). Information sharing allows firms to optimize inventories, effectively serve customers and manage capacity. This is in addition to optimizing delivery time and production schedules necessary for generating required revenue (Sampaio et al., 2016). Postponement is applicable to mitigate risks occasioned by products characterized by high monetary value and difficulty in demand prediction (Bagchi \& Gaur, 2018). Internal firm process management activities encompass research and development, product design and processes which dictate firm's level of productivity, time to market and employee performance important necessary for firms' competitiveness and improved performance (Zhong et al., 2016). Coordination of supply chain relates to managing transportation and logistics which integrates firms, suppliers and customers to minimize waste of efforts and time resulting in increased productivity, delivery time accuracy and customer satisfaction (Farnandes, Sampaio, \& Carvalho, 2014).

\subsection{Organizational Performance}

Organizational performance is a measure of the reward to or satisfaction level of stakeholders in return to their contribution to the organizations (Rouse \& Putterill, 2003). In this regard, such measures reveal extent to which explicitly or implicitly communicated organizational vision and mission respond to stakeholder expectations and requirement. Freeman (2010) conceptualizes stakeholders as a distinct group or individuals who influence or are controlled by goals of a firm. The author numerates stakeholders as employees, partners, community, governments and business owners. Therefore, a complete performance measurement model should 
capture financial, market, operational, societal, environmental, customer, learning and growth outcome facets which contends with the wish of the stake holders which was incorporated in this study. A good operating strategy must be geared towards yielding favorable impact on all the listed performance metrics. The six sub variables of SCQM practices considered in the study included; supplier quality management (SQM), customer focus (FC), information sharing (IS), postponement (P), process management (PM) and coordination of supply chain (CSC).

\subsection{Private Hospitals in Kenya}

Debates on what really constitutes private or public organizations are far from conclusion. The fundamental issues for categorization advanced in literature include; stockholding, profit motive, openness to external influence, scope of sharing benefits (communal or restricted to individuals), extent of accessing the health facilities, its resources or confidential information (Vries \& Huijsman, 2011; Awuor \& Kinuthia, 2013; WHO, 2015). Additional guide is whether the person or the organization is acting on behalf of the entire community or restricted to the individual. Based on the narrative, public organizations are confined to state owned and funded facilities. On the other hand, privately owned firms constitute those under total control and funded by individual(s), sales revenue or personal investments (Lachman, 1985). Private hospitals therefore encompass both for-profit and not-for-profit health entities that are not funded via exchequer and heavily influenced by their economic markets. Public and private hospitals compete with and complement each other in providing healthcare. There is also notable fierce competition among private hospitals since they presumably provide similar types of services (Turkyilmaz, Bulak, \& Zaim, 2015).

Both devolution and extended use of NHIF are Kenya's deliberate attempts to meet her heath care objectives, cater for high healthcare demand and provide health security at a reasonable cost. To attain equilibrium, managers of private hospitals in Kenya need to embrace modern approaches such as SCQM practices to reduce cost of operation, improve service quality, improve patient safety, generate adequate revenue and meet expectations of all other stakeholders. In the developing economies such as Kenya, demand for healthcare services in the private hospitals which overrides public counterparts has continued to grow in response to purportedly high quality of services, efficiency, the expanding middle class, higher health insurance penetration and low resource constraints (UNIDO, 2016). Kenya is still struggling to meet the goal of providing a universal healthcare. A research to present current data that can propel Kenya to achieve her healthcare goals and alleviate sufferings originating from poor health is an absolute necessity. 


\section{Literature Review}

2.1. Corporate Culture, Supply Chain Quality Management Practices and Organizational Performance.

Relational view posits that network members need inter-organizational cultural harmony to strategically bond together and merge resources such assets, knowledge and capabilities. This further competitively positions them at a better position among cohorts to achieve continuously improving firm performance (Fawcett et al., 2008; Prajogo \& McDermott, 2011). Conversely, corporate culture variability among firms may impede extent of SCQM practices implementation negating or weakening the link between the variable and organizational performance (Cadden et al., 2010; Vanichchinchai \& Igel, 2011). Additionally, contingency theory which proposes that cultural fit among networked organizations yields positive organizational performance outcomes due to aligned internal and external organizational conditions (Tuai, 2015). This implies that it is not the universality of appropriate internal conditions across organizations which guarantee firms success. Rather, the specific organizational attributes or contextual factors such as cultural orientation determine firms' effectiveness in implementing and sustaining SCQM practices so as to achieve competitive advantage that leads to enhanced organizational performance (Wadongo \& Abdel-Kader, 2014). This debate can be made crystal clear when context specific empirical data is collected and analyzed.

Rashid, Sambasivan \& Johari (2003) conducted a study to examine the influence of corporate culture and organizational commitment on financial performance in Malaysian companies. The researchers collected data from 202 managers in the public listed companies which confirmed that a significant correlation exists between corporate culture, organizational commitment and financial performance. Wei, Liu, Zhang and Chiu (2008) empirically sought to understand role played by corporate culture in the strategic human resource management (SHRMS) adoption and implementation among 223 Chinese enterprises. Results revealed that group and developmental cultures had positive impact on the adoption of SHRMS. However, hierarchical culture had insignificant impact. Further, developmental culture also had a direct effect on firm performance. Mailu, Ntale, and Ngui (2018) did a research to establish the effect of corporate culture in the relationship between strategy implementation and performance of 64 pharmaceutical companies in Nairobi Kenya. Using multiple regressions, the study confirmed that corporate culture has positive impact on the relationship. Indiya, Obura, \& Mise, J. K. (2018) conducted a study to find out the effect organizational culture has on performance of public universities in Kenya. The authors predicted possible outcome based on contingency theory. Data was gathered from 215 management staff of eleven public universities. The researchers used 
correlation as a research design and reported a strong positive correlation between organizational culture and performance.

While these studies underscore the importance of organizational culture in sparing performance growth, it falls short of clarifying the possible adhesive role of corporate culture in relationships and networks to trigger better performance. Secondly, the researchers report direct link between organizational culture and organizational performance with no indication of moderating effect of organizational culture. Other studies have emphasized the relevance of culture compatibility between firms in networks together with their customers in determining level of multi-dimensional performance (Mello \& Stank, 2005). Some have also reported significant relationship between corporate culture, operational strategies and influence of culture incongruence on differing levels of performance outcomes among firms (Cadden et al., 2010). These results suggest that organizational culture provides insight into the context dependence of supply chain quality management practices. Since nature of business conducted by firms shapes organization's culture, it would be interesting to confirm the exact role played by corporate culture in the relationship between SCQM practices adoption and performance of private hospitals in Kenya. The moderating effect of corporate culture is not expressly stated in the reviewed literature. The study was conducted to fill this gap left by past researchers.

\section{Conceptual Framework}

\begin{tabular}{|c|c|c|}
\hline & $\bar{T}$ & $\downarrow$ \\
\hline \begin{tabular}{ll} 
& \multicolumn{1}{c}{ SCQM Practices } \\
- & Supplier quality \\
& management \\
- & Customer focus \\
- & Information sharing \\
- & Postponement \\
- & Process management \\
- & Coordination of supply \\
& chain
\end{tabular} & $\begin{array}{l}\text { Corporate Culture } \\
\text { (Moderating Variable) } \\
\text { - } \quad \text { Quality of service } \\
\text { design } \\
\text { - } \quad \text { Quality of } \\
\text { products } \\
\text { - Conformance to } \\
\text { specifications }\end{array}$ & $\begin{array}{l}\text { Organizational Performance } \\
\text { (Dependent Variable) } \\
\text { - } \quad \text { Financial performance } \\
\text { - } \quad \text { Market performance } \\
\text { - } \quad \text { Environmental } \\
\text { - } \text { performance } \\
\text { - } \quad \text { Societal performance } \\
\text { - Operational performance } \\
\text { - } \quad \text { Learning and growth } \\
\text { - } \quad \text { Environmental } \\
\quad \text { performance }\end{array}$ \\
\hline
\end{tabular}

H1: The moderating effect of organizational factors on the relationship between SCQM practices and performance of private hospitals is significant 


\section{Research Methodology}

To test the resultant model informed by theories and literature review, positivist philosophy was adopted. Similarly, descriptive cross-sectional census survey research design was preferred to accommodate a low population of 158 private hospital as well as generate adequate data to facilitate use of covariance-based SEM for data analysis. The design is known to uncover the relationships among variables at a particular point in time (Saunders, Lewis \& Thornhill, 2007). The study targeted all private hospitals under category C according to National Hospital Insurance Fund (NHIF). From the NHIF website, there were 158 private hospitals categorized by NHIF as group C across Kenya as at June 2019. Data was collected by pharmaceutical professional sales representatives who routinely interact with management personnel using structured questionnaires. The respondents make decision on medical supply chain for the institutions. The tool was in form of five-point Likert-scale ranging from $1 \equiv$ not at all, $2 \equiv$ little extent, $3 \equiv$ some extent, $4 \equiv$ large extent and $5 \equiv$ very large extent was used to convert qualitative information into quantitative data. Drop and pick later strategy was preferred to give respondents adequate time to study the questionnaire and give accurate responses.

Corporate culture was operationalized as quality service design, consistency in offering quality products and conformance to specifications as suggested by Kuei et al (2001) and Vanichchinchin and Igel (2011). Completed questionnaires were picked by individual data collectors, sent via WhatsApp or email. Cronbach's Alpha value of 0.6 confirmed reliability of the questionnaire, item to total correlation value above 0.3 to ascertain reliability to the measuring scale, average variance extracted above 0.5 informed of high composite reliability, confirmatory factor analysis (CFA) above 0.4 verified construct validity. Further, AVE score above 0.5 indicated no convergent validity while heavy factor loading of indicators on the construct and FornellLarcker criterion for discriminant validity concluded the tests. All the readings were confined to the prescribed thresholds. Before proceeding to actual data analysis, normality, collinearity, homoscedasticity and autocorrelation model diagnostic tests were undertaken which were within the required cut offs. Individual 156 private health facilities comprised the unit of analysis and a single respondent was satisfactory.

\section{Data Analysis and Findings}

The study centered on all private hospitals in Kenya. From the National hospital Insurance database, a total of 158 private hospitals were identified to operate in Kenya. These are spread across all the forty-seven (47) counties in Kenya. Questionnaires were sent to all the 156 facilities. Out of the total, 121 questionnaires were received back implying that thirty-five (35) hospitals did 
not respond at all or in time due to a number of reasons. Explanations advanced include: challenges due to geographical distance, complicated policies, administrative procedures and snubbing by the target respondents to fill the provided questionnaire. The response rate was therefore $77.56 \%$. Upon scrutiny, eleven (11) questionnaires were found to have significant missing data on crucial research variables. Such questionnaires were purged from initial analysis which left a total of 110 fully filled questionnaires. The effective response rate was adjusted to $70.51 \%$.

Table 1: Demographic data of the private hospitals were as presented below.

Bed Capacity

\begin{tabular}{lccc}
\hline Bed capacity & Frequency & Percentage & Cumulative Percentage \\
\hline Below 100 & 72 & 65.5 & 65.5 \\
$100-250$ & 30 & 27.3 & 92.7 \\
Over 250 & 8 & 7.3 & 100 \\
\hline Total & 110 & 100 & \\
\hline Age (Years) & \multicolumn{3}{c}{} \\
\hline Less than 10 & 28 & 25.5 & 68.2 \\
$10-20$ & 47 & 42.7 & 100 \\
Over 20 & 35 & 31.8 & \\
\hline Total & 110 & 100 & \\
\hline \multicolumn{4}{c}{ Source: Research data, 2019 }
\end{tabular}

Corporate culture was measured using three indicators namely; quality service design, consistently offer quality products and conform to specifications. The elements were rated on a five-point Likert scale ranging from one (1) denoting "not at all" to five (5) representing "very great extent" as synopsized in the table below:

Table 2: Corporate Culture

\begin{tabular}{lccccc}
\hline & Mean & SD & $\begin{array}{c}\text { Factor } \\
\text { loading }\end{array}$ & $\begin{array}{c}\text { Item-total } \\
\text { correlation }\end{array}$ & Alpha if item deleted \\
\hline $\begin{array}{l}\text { Quality service design } \\
\begin{array}{l}\text { Consistently offer quality } \\
\text { products }\end{array}\end{array}$ & 3.34 & 1.007 & .459 & .437 & .563 \\
Conform to specifications & 3.71 & 1.028 & .536 & .482 & .499 \\
\hline
\end{tabular}

Cronbach's Alpha=.684, Grand Mean=3.53. Source: Primary research data, 2019

Conforming to specifications was ranked highest at 3.71 ( $\mathrm{SD}=1.087$, $\mathrm{N}=110$ ) followed by offering consistently quality products at 3.55 ( $\mathrm{SD}=$ $1.028, \mathrm{~N}=110)$ while quality service design was ranked lowest at $3.34(\mathrm{SD}=$ 1.007, $\mathrm{N}=110$ ). On the whole, corporate culture was mean rated at 3.53 implying that private hospitals implemented the practice to a great extent. Factor loadings for the elements ranged from 0.459 to 0.644 . Cronbach's Alpha was 0.684 while item to total correlation ranged from 0.437 to 0.482 , a higher value than the threshold of 0.3 . The three items met the prescribed cut 
offs for reliability and construct validity to allow progress to model determination.

Chi-Square $\left(\chi^{2}\right)$ fit test, Standard Root Mean Square Residual (SRMR), Goodness of Fit Index (GFI) and Root Mean Square Error of Approximation (RMSEA) were used to assess the model fitness before interpretation of the findings. Chi square test that is recommended for sample range between 100 and 200 as was the case in this study had a value of 3.869, the degrees of freedom was 117. The Chi-Square was insignificant at 0.05 level of significance and lower than the degree of freedom. This confirms model fitness. Additionally, SRMR (0.039) and GFI (0.787) were within the prescribed limits of $\leq 0.05$ and $\geq 0.9$ respectively. RMSEA value was 0.0429 and the expected value was $\leq 0.05$. Apart from GFI, other observed values confirmed that the condition of model fitness was met to permit further analysis and interpretation. Motawa \& Oladokun, (2015) found a value of 0.774 but proceeded with analysis since the value can be affected by small sample size. In this case 110 sample size falls in the lower continuum.

Table 3: Model Fit Statistics for Moderation Effect of Corporate Culture

\begin{tabular}{lccccc}
\hline Model & $\chi^{2}$ & Df & SRMR & RMSEA & GFI \\
\hline Default model & 3.869 & 117 & 0.039 & 0.0429 & .787 \\
\hline
\end{tabular}

Source: Primary research data, 2019

Corporate culture was subjected to analysis as a moderating variable to determine its effect on the relationship between SCQM practices adoption and organizational performance. The independent variable, SCQM practices was entered into AMOS followed by corporate culture and then the interaction term of SCQM practices and corporate culture. AMOS graphic with path coefficients was developed and presented as shown in figure below.

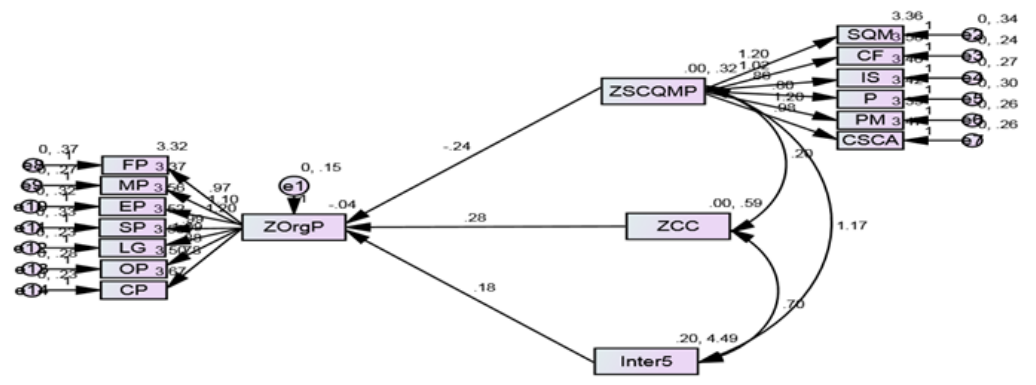

Structural Equation Modelling Path Diagram for the Moderating Effect of Corporate Culture on the relationship between SCQM Practices and Organizational Performance 
Organizational performance (ORP) as endogenous latent construct (OP) was measured in terms of Financial Performance (FP), Market (MS), Societal Impact (SI), Operational Performance, Learning and Growth (LG) and Environmental Impact (EI). The six items used to measure SCQM practices were; Supplier Quality Management (SQM), Customer Focus (FC), Information Sharing (IS), Postponement (P), Process management (PM) and Coordination of Supply Chain (CSC). CC denotes corporate culture.

Table 4 bellow gives a summary of objectives, hypothesis, data analysis, decision Criteria, interpretation and remarks of the study

Table 4: Summary of Objectives, Hypothesis, Analysis and Decision Criteria

\begin{tabular}{|c|c|c|c|c|c|}
\hline Objective & Hypothesis & $\begin{array}{l}\text { Data } \\
\text { analysis }\end{array}$ & $\begin{array}{l}\text { Decision } \\
\text { Criteria }\end{array}$ & Results & $\begin{array}{l}\text { Interpretation } \\
\text { and remarks }\end{array}$ \\
\hline ablish & Hypothesis & CB-SEM & Chi square & $\chi^{2}=3.869, p>0.05 ; \mathrm{SRMR}=$ & Hypothesis $2 \mathrm{e}$ \\
\hline the role of & 1: The & analysis - & (insignific & $0.039, \mathrm{p}<0.05 ;$ GFI $=0.787$ & is supported. \\
\hline & moderating & & $.05)$ & RMSEA $=0.0429, p<0.05$ & This implies \\
\hline in the & effect of & GF & $\mathrm{SRMR} \leq$ & Results showed that SCQM & sign \\
\hline relationship & corporate & SRMR, & $0.08, \mathrm{GFI}$ & practices have a significant & moderating \\
\hline between & $\begin{array}{l}\text { culture on } \\
\text { the }\end{array}$ & RMSEA & $\geq 0.9$ and & positive effect on the & effect of \\
\hline practices and & $\begin{array}{l}\text { the } \\
\text { relationship }\end{array}$ & cion & $\begin{array}{l}\text { RIMSEA } \leq \\
0.08 . \mathrm{H}_{2 \mathrm{e}}\end{array}$ & $\begin{array}{l}\text { performance of private hospitals } \\
(\beta=0.236, t=4.367, p<0.001)\end{array}$ & $\begin{array}{l}\text { corporate } \\
\text { culture on the }\end{array}$ \\
\hline performance & between & e of & is not & The effect of corporate culture on & relationship \\
\hline of $\mathrm{Pr}$ & SCQMP and & coefficient & rejected if & the performance of private & between \\
\hline hospitals in & OP of private & & p-value of & hospitals is also positive and & SCQM \\
\hline & significant & & $\begin{array}{l}\text { coefficient } \\
\text { is } \leq 0.05\end{array}$ & $\begin{array}{l}\mathrm{p}<0.001) . \text { The effect of the } \\
\text { interaction term on the } \\
\text { performance of private hospital is } \\
\text { also positive and insignificant }(\mathrm{r} \\
=0.184, \mathrm{t}=2.015, \mathrm{p}=044) . \mathrm{R}^{2}= \\
0.514\end{array}$ & $\begin{array}{l}\text { performance of } \\
\text { private } \\
\text { hospitals }\end{array}$ \\
\hline
\end{tabular}

\section{Test of Hypothesis, Interpretations and Discussion}

5.1. Corporate Culture, Supply Chain quality Management Practices and Organizational Performance

Hypothesis that Corporate culture significantly moderates the relationship between SCQM practices and organizational performance was confirmed. This is consistent with past findings (Meirovich, 2010; Prajogo \& Mcdermott, 2011; Maiga, 2015; Lin, Kuei \& Chai, 2013). A firm that has culture of motivation, knowledge and good attitude to implement SCQM practices benefit from high level of performance. The result is better if this culture is shared among trading partners, customers and implied stakeholders (Lee \& Yu, 2013). Mello and Stank (2005) confirmed that corporate culture and orientation directly contributes to SCQM practices success. The authors concluded that an organization must ensure effective cultural change that is aligned to SCQM practices for it not to become an artifact of corporate fad. 
Given the inter-organizational nature of SCQM practices, it is posited that partners must have cultural similarities to realize any meaningful gains (Meirovich, 2010). The findings support the relevance of network theory and general contingency theory in the prediction of the effect. The wider the cultural gaps are between partners, the more the dismal performance outcome as a result failed SCQM practice (Cadden et al., 2010).

\section{Conclusion, Recommendations and Implications}

It was ascertained that corporate culture positively and significantly moderates the relationship between SCQM practices and performance of private hospitals. There was a positive significant path between SCQM practice and organizational performance, a positive and significant path between the moderator and organizational performance and a positive and significant path between the interaction term and organizational performance for corporate culture as a construct.Corporate culture has a significant moderating effect on the relationship between SCQM practices and the performance of private hospitals. This reveals that for relationships in supply chain to thrive, appropriate corporate culture must be ensured in private hospitals. Cultural incongruency among supply chain members should be kept minimal if not eliminated. This enables firms to interpret the benefit of quality management at equal wavelength to support implementation across the organizations. The study recommends that organizations must make tangible efforts to align culture with their operating strategies. The right corporate culture is a key element in the implementation of SCQM practices to bring about improved performance (Meirovich, 2010; Kushwaha \& Barman, 2010; Lee et al., 2013; Lin et al., 2013). The implication is that corporate culture denotes long term commitment by the organizations to quality along the supply chain. Based on social network theory relationships flourish when harmonized corporate culture prevails within organizations and beyond their boundaries (He et al., 2018).

\section{Suggestions for Further Research}

In this study cross-sectional census survey was adopted. Given the dynamic nature of organizations, future studies need to consider the option of longitudinal research to assess the alterations occasioned by situations and business landscape dynamics. The study was confined to private hospital in Kenya as per National Hospital Insurance Fund definition. Future studies should extend beyond the Kenyan borders, cover other industries and involve greater geographical areas. Further, the studies should include mission, public and not for profit hospitals to allow for comparisons. The cultural dissimilarities are likely to be revealed in SCQM practices. In future, research orientation needs to lean towards investigating quality approaches and 
methods across cultures. Such a research is likely to reveal global information that can be used as a foundation for international comparative studies on SCQM practices, corporate culture and performance.

\section{References:}

1. Abd Rahman, A., Kamarulzaman, N. H., \& Sambasivan, M. (2013). A study on organizational culture, performance, and technological adoption behaviors of Malaysian food-processing SMEs. Pertanika Journal of Social Sciences \& Humanities, 21, 231-256.

2. Awuor, O.E., \& Kinuthia, D.M.W (2013). Total Quality Management Practices in Selected Private Hospitals in Nairobi, Kenya. European Journal of Business and Management. 5(13),32-44.

3. Bagchi, S. S, \& Gaur, J (2018). Optimization of postponement process for a two-stage modular manufacturer. Journal of Global Operations and Strategic Sourcing, 11(1), 39-54.

4. Cadden, T., Humphreys, P. \& McHugh, M. (2010). The influence of organizational culture on strategic supply chain relationship success. Journal of General Management, 36 (2) 37-61.

5. Deshpande', R. \& Farley, J.U. (2013). Organizational culture, market orientation, innovativeness, and firm performance: an international research odyssey. International Journal of Research in Marketing, 21 (1), 53-73.

6. Fawcett, S.E., Magnan, G.M. \& McCarter, M.W. (2008). Benefits, barriers, and bridges to effective supply chain management. Supply Chain Management: An International Journal, 13(1), 35-48.

7. Fernandes, A. C., Sampaio, P., \& Carvalho, M. S. (2014). Quality management and supply chain management integration: a conceptual model. IEOM, 773-780.

8. Freeman, R. E. (2010). Strategic management: A stakeholder approach. Cambridge university press.

9. He, Y., Sun, H., Ni, W., \& Ng, S.C.H (2017). Re-examining the effects of supplier integration on operations performance: a relational view. International Journal of Operations \& Production Management, 37 (12), 1702-1721.

10. Indiya, G. D., Obura, J., \& Mise, J. K. (2018). Effect of Organization Culture on organization performance on Public Universities in Kenya.

11. Kushwaha, G. S., \& Barman, D. (2010). Development of a theoretical framework of supply chain quality management. Serbian Journal of Management, 5(1), 127-142.

12. Lachman, R. (1985) Public and private sector differences: CEO's perceptions of their role environments. Academy of Management Journal, 28, 671-679. 
13. Lee, S.K.J. \& Yu, K. (2013). Corporate culture and organizational performance. Journal of Managerial Psychology, 19 (4), 340.

14. Lee, S. M., Lee, D., \& Schniederjans, M. J. (2011). Supply chain innovation and organizational performance in the healthcare industry. International Journal of Operations \& Production Management, 31(11), 1193-1214.

15. Lin, C., Kuei, C. H., \& Chai, K. W. (2013). Identifying critical enablers and pathways to high performance supply chain quality management. International Journal of Operations \& Production Management, 33(3), 347-370.

16. Prajogo, D.I. \& McDermott, C. (2011). The relationship between multidimensional organizational culture and performance. International Journal Operations and Production Management, 31(7), 712-35.

17. Maiga, A. S. (2015). Organizational Learning and Firm Profitability: The Role of Competitive Advantage. Advances in Accounting Behavioral Research, 179-211.

18. Mailu, R. N., Ntale, J. F., \& Ngui, T. K. (2018). Strategy implementation and organizational performance in the pharmaceutical industry in Kenya. International Academic Journal of Human Resource and Business Administration, 3(2), 33-47.

19. Mello, J.E. \& Stank, T.P. (2005). Linking firm culture and orientation to supply chain success. International Journal of Physical Distribution and Logistics Management, 35 (7/8), 542-54.

20. Meirovich, G. (2010). The impact of cultural similarities and differences on performance in strategic partnerships: an integrative perspective. Journal of Management and Organization, 6, 127-39.

21. Motawa, I., \& Oladokun, M. (2015). A model for the complexity of household energy consumption. Energy and Buildings, 87, 313-323.

22. Rashid, M.Z.A., Sambasivan, M. \& Johari, J. 2003. The influence of corporate culture and organizational commitment on performance. Journal of Management Development 22(8): 708-728

23. Sampaio, P., Carvalho, M. S., Fernandes, A. C., Quang, H. T., An, D. T. B., \& Vilhenac, E. (2016). An extensive structural model of supply chain quality management and firm performance. International Journal of Quality \& Reliability Management, 33 (4), 444-464

24. Saunders, M., Lewis, P. \& Thornhill, A. (2007) Research Methods for Business Students (3)54-95.

25. Sun, S. (2008). Organizational culture and its themes. International Journal of Business and Management, 3(12), 137-141.

26. Talib, F., Rahman, Z., \& Qureshi, M.N. (2011). A study of total quality management and supply chain management practices. 
International Journal of Productivity and Performance Management, 60(3), 268-288.

27. Turkyilmaz, A., Bulak, M. E., \& Zaim, S. (2015). Assessment of TQM Practices as a part of supply chain management in healthcare institutions. International Journal of Supply Chain Management, 4(4), $1-9$.

28. Rouse, P \& Putterill, M. (2003). An integral framework for performance measurement Management Decision, 41(8), 791-805

29. UNIDO Pharmaceutical Sector profile Kenya: Global UNIDO Project (2016): Retrieved from: http://www.unido.org on 1-8-2013

30. Vanichchinchai, A., \& Igel, B. (2011). The impact of total quality management on supply chain management and firm's supply performance. International Journal of Production Research, 49(11), 3405-342.

31. Vries, J., \& Huijsman, R. (2011). Supply chain management in health services: an overview. Supply Chain Management: An International Journal, 16(3), 159-165.

32. Wei, L. Q., Liu, J., Zhang, Y., \& ChLu, R. K. (2008). The role of corporate culture in the process of strategic human resource management: Evidence from Chinese enterprises. Human Resource Management, 47(4), 777-794

33. Zeng, J., Phan, C.A. \& Matsui, Y. (2013). Supply chain quality management practices and performance: An empirical study. Operations management research 6(2), 19-31

34. Zhong, J., Ma, Y., Tu, Y., \& Li, X. (2016). Supply chain quality management: an empirical study. International Journal of Contemporary Hospitality Management, 28(11). 